\title{
Hubungan Pengetahuan dengan Kepatuhan Bidan dalam Penggunaan Partograf di Kamar Bersalin RSUD Undata Palu
}

\author{
Laura Rantalaen, Vira Pratiwi ${ }^{\star}$, Ni Made Rosiyana \\ Diploma III Kebidanan AKBID Palu \\ *Email korespondensi: virapratiwi@yahoo.com
}

Article Info

ABSTRACT

Article history:

Submitted: 2019-02-26

Accepted: 2019-04-22

Published: 2019-08-31

Keywords:

Knowledge;

Compliance;

Partograph;

Compliance in the use of partographs is one of the most important thing done by midwives to make clinical decisions, monitoring, evaluation, handling labor, early problem detection and complicated labor so that they can plan actions to overcome the problem or to give refferal the mother in the right conditions. The purpose of this study was to find out the relationship between knowledge with the compliance of midwives in the use of partographs. This study used an analytical observational design with a cross-sectional approach. The subjects in the study were all midwives who worked in the Maternity Room of Undata Palu Hospital in March-June 2018 as many as 26 respondents. Bivariate analysis used the Sperman Rank test. The results of this study were good knowledgeable midwives as many as 18 respondents $(69.3 \%)$, obedient midwives as many as 16 respondents $(61.5 \%)$, and the results of bivariate analysis showed that the relationship of knowledge with midwife compliance in using partograph was rs 0.529 and p-value 0.005 . Conclusion: There was a relationship between knowledge and compliance of midwives in using Partographs with medium correlation strength. Suggestion: This result can be an evaluation material for respondents about the use of partograph.

\section{ABSTRAK}

\section{Kata Kunci:}

Pengetahuan;

Kepatuhaan;

Partograf;

\begin{abstract}
Kepatuhan dalam penggunaan partograf merupakan salah satu hal yang sangat penting dilakukan oleh seorang bidan untuk membuat keputusan klinik, memantau, mengevaluasi, menangani persalinan, mendeteksi dini masalah dan penyulit dalam persalinan, sehingga dapat merencanakan tindakan mengatasi masalah tersebut atau merujuk ibu dalam kondisi yang tepat. Tujuan penelitian ini diketahuinya hubungan pengetahuan dengan kepatuhan bidan dalam penggunaan partograf. Penelitian ini menggunakan desain observasional analtik dengan pendekatan cross sectional. Subyek dalam penelitian adalah semua bidan yang bekerja di Kamar Bersalin RSUD Undata Palu pada bulan Maret-Juni Tahun 2018 sebanyak 26 responden. Analisa bivariat menggunakan uji Sperman Rank. Hasil penelitian ini adalah bidan berpengetahuan baik sebanyak 18 responden $(69,3 \%)$, bidan yang patuh sebanyak 16 responden $(61,5 \%)$, dan hasil analisa bivariat diperoleh bahwa hubungan pengetahuan dengan kepatuhan bidan dalam penggunaan partograf adalah rs 0,529 dan nilai p 0,005. Kesimpulan: ada hubungan antara pengetahuan dengan kepatuhan bidan dalam penggunaan Partograf dengan kekuatan korelasi sedang. Saran: sebagai bahan evaluasi bagi responden dalam penggunaan partograf
\end{abstract}




\section{PENDAHULUAN}

Partograf merupakan sebuah grafik yang dapat membantu memantau kemajuan kala I persalinan dan informasi untuk membuat keputusan klinik. ${ }^{1}$ Manfaat partograf bagi bidan atau tenaga kesehatan penolong persalinan lainnya adalah agar dapat mengetahui lebih awal bila terjadi kelainan dalam proses persalinan. Ketika digunakan secara akurat dan konsisten, dapat mengurangi morbiditas dan mortalitas ibu dan perinatal karena persalinan lama, disproporsi sefalopelvis, persalinan terhambat dan asfiksia neonatal. ${ }^{2,3}$

Penggunaan yang efektif dari partograf, seorang bidan harus memiliki pemahaman yang komprehensif tentang fungsi partograf dan harus terus memantau, mendokumentasikan dan menafsirkan informasi yang dikumpulkan untuk deteksi dini dan pencegahan komplikasi maternal dan neonatal. ${ }^{4}$ Penggunaan partograf dalam kaitannya dengan inovasi atau perubahan yang dilakukan terhadapnya dipengaruhi oleh perbedaan pengetahuan, sikap, kesadaran, dan keyakinan pengasuh dalam penggunaannya; supervisi suportif reguler; jaminan kualitas dan konteks organisasi. ${ }^{5}$

Dampak dari kelalaian pengisian partograf adalah tidak terdeteksinya kelainan yang mungkin akan timbul pada saat persalinan, seperti gawat janin, hipertensi, partus lama, dan perdarahan, karena 15\% dari komplikasi pada persalinan tidak dapat diprediksi. Bidan merupakan salah satu tenaga kesehatan yang terlibat langsung dalam pertolongan persalinan sehingga perilaku dan tindakan pada saat memberikan asuhan menjadi sangat penting dalam upaya penurunan angka morbiditas dan mortalitas karena persalinan yang ditolong oleh tenaga kesehatan $85 \%$ nya ditolong oleh bidan. ${ }^{6}$

Kepatuhan bidan merupakan sikap patuh atau taat terhadap peraturan yang telah disepakati, banyak faktor yang mempengaruhi kepatuhan seorang bidan yaitu, pengetahuan, sikap, umur, beban kerja, lama kerja, tingkat pendidikan, sarana fasilitas yang tersedia. Penilaian terhadap pengetahuan dan kepatuhan bidan tentang partograf perlu dilaksanakan untuk mengetahui sejauh mana kesiapan bidan dalam menangani suatu persalinan. ${ }^{7}$

Pengetahuan merupakan hasil dari tahu yang terjadi setelah seseorang melakukan penginderaan terhadap objek tertentu. Sikap seseorang terhadap suatu objek menunjukkan pengetahuan mengenai objek tersebut. Pengetahan merupakan faktor yang sangat penting untuk terbentuknya perilaku seseorang dalam hal ini adalah kepatuhan bidan dalam penggunaan partograf. ${ }^{8}$

Salah satu faktor yang sering menyebabkan mortalitas dan morbiditas pada ibu bersalin adalah partus lama. Partus lama terjadi apabila persalinan berlangsung lebih dari 24 jam pada primigravida dan lebih dari 18 jam pada multigravida. Partus lama akan menyebabkan infeksi, kehabisan tenaga, dehidrasi pada ibu, kadang dapat terjadi perdarahan post partum yang dapat menyebabkan kematian ibu. Pada janin akan terjadi infeksi, cedera dan asfiksia yang dapat meningkatkan kematian bayi. Untuk memantau dan mengobservasi persalinan, melalui asuhan persalinan normal. mengandalkan penggunaan partograf untuk memantau kondisi ibu dan janin serta kemajuan proses persalinan sehingga penolong persalinan (bidan, perawat, dokter umum, atau spesialis obstetri) dapat membuat keputusan klinik sebagai upaya pengenalan adanya gangguan proses persalinan atau komplikasi dini agar dapat memberikan tindakan yang paling tepat dan memadai. ${ }^{9}$

Berdasarkan pengambilan data awal yang peneliti lakukan di Kamar Bersalin RSUD Undata Palu, jumlah persalinan pada tahun 2016 terdapat 417 jiwa. pada tahun 2017 terdapat peningkatan menjadi 493 sampai dengan bulan september. Dan 
jumlah persalinan dengan secsio caesaria berjumlah 90 orang ibu dan terdapat 224 orang ibu yang menjalani persalinan normal Sedangkan jumlah bidan keseluruhan pada tahun 2017 berjumlah 94 bidan orang, jumlah bidan di kamar bersalin 26 orang. Tujuan Umum penelitian ini adalah diketahui adanya hubungan pengetahuan dengan kepatuhan bidan dalam penggunaan partograf di Kamar Bersalin RSUD Undata Palu.

\section{METODE PENELITIAN}

Jenis penelitian yang digunakan adalah penelitian observasional analitik korelasional dengan pendekatan cross sectional. Penelitian ini telah dilakukan di Kamar Bersalin RSUD Undata Palu selama 3 bulan (28 Maret - 02 Juni-2018). Populasi dalam penelitian ini adalah Bidan yang bekerja di kamar bersalin di RSUD Undata Palu. Peneliti menggunakan teknik total sampling dengan sampel berjumlah 26 orang. Tehnik pengumpulan Data menggunakan Kuesioner yang berisi 10 pertanyaan pengetahuan dengan skala Ordinal. Pengelolaan data melalui mengedit, memberikan kode, membuat tabel, koreksi data, dan mendeskripsikan data yang sudah dikumpulkan. Penyajian data dalam bentuk tabel dan narasi. Analisa data menggunakan analisa univariat dengan rumus presentasi dan analisa bivariat dengan uji korelasi Spearman Rank. Korelasi Spearman digunakan pada data yang berskala ordinal semuanya atau sebagian data adalah ordinal. untuk itu sebelum dilakukan pengolahan data, data yang akan dianalisis perlu disusun dalam bentuk ranking.

\section{HASIL PENELITIAN}

Setelah data penelitian dianalisis maka diperoleh hasil sebagai berikut:

Tabel 1: Karakteristik Bidan di Kamar Bersalin RSUD Undata Palu

\begin{tabular}{ccc}
\hline Variabel & Frekuensi & $\begin{array}{c}\text { Presentase } \\
\%\end{array}$ \\
\hline $\begin{array}{ccc}\text { Umur } \\
\text { 20-35 tahun }\end{array}$ & 20 & 76,9 \\
> 35 tahun & 6 & 23,1 \\
Pendidikan & & \\
DIII & 9 & 34,6 \\
DIV & 17 & 65,3 \\
Pekerjaan & & \\
PNS & 24 & 92,3 \\
Honorer & 2 & 7,6 \\
Pengetahuan & & \\
Baik & 18 & 69,3 \\
Kurang Baik & 8 & 30,7 \\
Kepatuhan & & \\
Patuh & 16 & 61,5 \\
Tidak Patuh & 10 & 36,5 \\
\hline
\end{tabular}

Sumber : Data primer, 2018

Tabel 1 menunjukan 76,9\% responden berumur 20-35 tahun, 65,3\% berpendidikan D-IV, 92,3\% PNS. 69,3\% responden berpengetahuan baik, dan 61,5\% yang patuh menggunakan partograf 
Tabel 2: Hubungan Pengetahuan dengan Kepatuhan Bidan dalam Penggunaan Partograf di Kamar Bersalin RSUD Undata Palu

\begin{tabular}{lcccccc}
\hline \multirow{3}{*}{ Pengetahuan } & \multicolumn{4}{c}{ Kepatuhan } & \multirow{2}{p}{-value } \\
\cline { 2 - 5 } & \multicolumn{2}{c}{ Patuh } & \multicolumn{2}{c}{ Tidak patuh } & $\begin{array}{c}\text { Spearman } \\
\text { Rank }\end{array}$ \\
\cline { 2 - 5 } & $\mathbf{n}$ & $\%$ & $\mathbf{n}$ & $\%$ & 0,005 \\
Baik & 18 & 69,3 & 10 & 38,5 & \\
Kurang Baik & 16 & 61,5 & 8 & 30,7 & \\
\hline
\end{tabular}

Sumber : Data primer, 2018

\section{PEMBAHASAN}

Responden yang berpengetahuan baik rata-rata berumur $>35$ tahun, dan lulusan D3-D4. Umur merupakan lama hidup yang dihitung sejak dilahirkan. ${ }^{10}$ Semakin bertambah umur seseorang, semakin bertambah pula daya tangkapnya. Seseorang dengan umur semakin bertambah, akan semakin baik dalam menentukan pilihan karena sudah banyak menerima informasi dari lingkungan sekitar, teman, tetangga, dan orang tua.

Menurut Green, bahwa umur termasuk faktor pemudah (predisposing factor), faktor ini dapat berpengaruh langsung terhadap terjadinya perilaku seseorang. Sehingga disimpulkan bahwa umur dapat mempengaruhi pengetahuan, seseorang yang lebih dewasa lebih dipercaya daripada orang yang belum tinggi kedewasaannya. Hal itu sejalan dengan pengalaman dan kematangan jiwa.

Untuk tingkat kepatuhan responden terhadap partograf dalam persalinan, dari kelompok umur 20-43 tahun dari 26 responden, yang patuh $16(61,5 \%)$ responden, sedang yang tidak patuh 10 (38,5\%). responden Dari tingkat pendidikan responden pada tabel 4.1 menunjukkan bahwa sebagian besar adalah berpendidikan D III yaitu 9 orang $(34,6 \%)$ responden dengan pendidikan D IV sebanyak 16 orang $(61,6 \%)$ responden.

Menurut Notoatmodjo sikap dan tindakan seseorang yang didasari oleh pendidikan akan lebih langgeng. ${ }^{11}$ Tingkat pendidikan bidan akan menentukan sikap patuh terhadap tindakannya dalam menghadapi berbagai masalah. Bidan yang berpendidikan tinggi semakin mudah menyerap informasi sehingga memiliki persepsi yang lebih baik dibandingkan dengan yang berpendidikan rendah. Orang yang berpendidikan tinggi akan memberikan respon yang lebih rasional terhadap informasi yang datang dan akan berperilaku yang lebih banyak memberikan keuntungan.

Pengetahuan (knowledge) merupakan hasil rasa keingintahuan manusia terhadap sesuatu dan hasrat untuk meningkatkan harkat hidup sehingga kehidupan menjadi lebih baik dan nyaman sehingga yang berkembang sebagai upaya untuk memenuhi kebutuhan manusia baik dimasa sekarang maupun dimasa depan. Pengetahuan hanya sekedar menjawab pertanyaan what, misalnya alam, manusia, air. ${ }^{12}$

Kepatuhan bidan merupakan sikap patuh atau taat terhadap peraturan yang telah disepakati, banyak faktor yang mempengaruhi kepatuhan seorang bidan yaitu, pengetahuan, sikap, umur, beban kerja, lama kerja, tingkat pendidikan, sarana fasilitas yang tersedia. Penilaian terhadap pengetahuan dan kepatuhan bidan tentang partograf perlu dilaksanakan untuk mengetahui sejauh mana kesiapan bidan dalam menangani suatu persalinan. ${ }^{7}$

Sebuah penelitian di Nigeria menunjukkan bahwa hanya $8,4 \%$ responden yang menggunakan partograf untuk memantau persalinan. ${ }^{13}$ Sebaliknya, dalam sebuah penelitian yang dilakukan pada pengetahuan dan pemanfaatan partograf di antara 
pemberi perawatan kebidanan di institusi kesehatan masyarakat Addis Ababa lebih dari $50 \%$ dari pemberi perawatan kebidanan menggunakan partograf untuk memantau persalinan. ${ }^{14}$ Lain, Studi yang dilakukan di wilayah Amhara tentang pemanfaatan partograf mengungkapkan hanya 29\% dari makalah paragraf yang ditinjau diisi dengan benar untuk memantau kemajuan persalinan. ${ }^{15}$

Menurut asumsi peneliti penggunaan partograf pada saat pertolongan persalinan oleh bidan merupakan hal yang sangat penting. Bidan yang tidak patuh dalam penggunaan partograf berdampak bagi kesehatan ibu dan janin. Dampak dari kelalaian pengisian partograf adalah tidak terdeteksinya kelainan yang mungkin akan timbul pada saat persalinan, seperti gawat janin, hipertensi, partus lama, dan perdarahan, karena $15 \%$ dari komplikasi pada persalinan tidak dapat diprediksi. Dalam hal ini Bidan merupakan salah satu tenaga kesehatan yang terlibat langsung dalam pertolongan persalinan sehingga perilaku dan tindakan pada saat memberikan asuhan menjadi sangat penting, tetapi masih ditemukan bidan tidak menggunakan partograf dalam pemantauan persalinan. Dari hasil survei peneliti masih ada sebagian bidan yang melakukan pemeriksaan kemajuan persalinan (pembukaan) tidak langsung mengisi di lembar partograf melainkan di kertas observasi atau status pasien.

Hasil penelitian ini menunjukan bahwa terdapat hubungan antara pengetahuan dengan kepatuhan bidan dalam penggunaan patograf di kamar bersalin RSUD Undata Palu. Hasil penelitian ini sejalan dengan penelitian Mobiliu bahwa ada hubungan signifikan antara pengetahuan bidan dengan penggunaan penerapan partograf. ${ }^{1}$

Penelitian di India ditemukan hanya 37,3\% responden yang memiliki praktik yang baik dalam penerapan partograph, namun setelah dilakukan intervensi naik menjadi 52,9\% dan ketika dievaluasi 3 bulan setelah pelatihan naik lagi menjadi $58,8 \%$. Penguatan dan dukungan terus-menerus dengan supervisi akan memungkinkan bidan untuk mempraktikkan partograf secara memadai. ${ }^{16}$

Menurut peneliti masih banyak bidan yang tidak patuh dikarenakan masih kurangnya pengetahuan mereka tentang partograf hal itu juga dipengaruhi oleh umur, dimana umur dapat menentukan lama hidup, pengalaman dan kematangan jiwa. Kemudian pendidikan seseorang juga mempengaruhi tindakan dalam mengambil keputusan, karena pengetahuan seseorang juga diukur dari tingkat pendidikannya semakin tinggi pendidikanya maka semakin banyak ilmu yang didapatkan. karena apabila seseorang tersebut memiliki pengetahuan yang tinggi tentang partograf itu sendiri maka sebagai seorang bidan yang menangani persalinan akan melaksanakan dengan benar atau patuh terhadap ketentuan penggunaan partograf tersebut.

\section{SIMPULAN DAN SARAN}

Lebih banyak pengetahuan bidan yang baik tentang partograf di Kamar bersalin RSUD Undata Tahun 2018. Lebih banyak bidan yang patuh dalam Penggunaan Partograf di Kamar bersalin RSUD Undata. Jadi, ada hubungan Tingkat Pengetahuan dengan Kepatuhan Bidan dalam Penggunaan Partograf di Kamar bersalin RSUD Undata dengan tingkat korelasi sedang. Saran peneliti, diharapkan penelitian ini dapat meningkatkan pengetahuan dan konsistensi bidan dalam menerapkan partograf secara lengkap untuk mendeteksi dengan cepat komplikasi yang bisa terjadi. 


\section{DAFTAR PUSTAKA}

1. Mobiliu S. Hubungan Pengetahuan Bidan Dengan Penerapan Penggunaan Partograf di Ruang Kebidanan RSUD Toto Kabila Kabupaten Bone Bolango. J Heal Sport. 2012;5(3):656-65.

2. Qureshi Z, Sekadde- Kigondu C, Mutiso S. Rapid assessment of partograph utilisation in selected maternity units in Kenya. East Afr Med J [Internet]. 2011 Jan 7;87(6). Available from: http://www.ajol.info/index.php/eamj/article/view/63081

3. Zelellw D, Tegegne T. The Use and Perceived Barriers of the Partograph at Public Health Institutions in East Gojjam Zone, Northwest Ethiopia. Ann Glob Heal [Internet]. 2018 Apr 30;84(1):198. Available from: https://annalsofglobalhealth.org/articles/10.29024/aogh.23

4. Asp G, Sandberg J, Ezechi O, Pettersson KO. Challenges of immediate newborn care in maternity units in Lagos, Nigeria: An observational study. J Obstet Gynaecol (Lahore) [Internet]. 2011 Oct 5;31(7):612-6. Available from: http://www.tandfonline.com/doi/full/10.3109/01443615.2011.593652

5. Ollerhead E, Osrin D. Barriers to and incentives for achieving partograph use in obstetric practice in low- and middle-income countries: a systematic review. BMC Pregnancy Childbirth [Internet]. 2014 Dec 16;14(1):281. Available from: http://bmcpregnancychildbirth.biomedcentral.com/articles/10.1186/1471-2393-14-281

6. Badan Kependudukan dan Keluarga Berencana Nasional, Badan Pusat Statistik, Kementerian Kesehatan R.I., ICF International. Survei Demografi dan Kesehatan Indonesia 2012. Jakarta: Badan Kependudukan dan Keluarga Berencana Nasional; 2013.

7. Sutaip S, Mawarni A, Dharmawan Y. Faktor-Faktor yang Berhubungan dengan Kinerja Pelaporan Data Pelayanan KIA oleh Bidan Praktek Swasta di Kota Semarang Tahun 2012. J Kesehat Masy. 2012;1(2):206-17.

8. Syafrudin \& Hamidah. Kebidanan Komunitas. I. Monica Ester \& Esty Wahyuningsih, editor. Jakarta: Buku Kedokteran EGC; 2009.

9. Wiknjosastro H. Ilmu Kandungan. Jakarta: Yayasan Bina Pustaka Sarwono Prawirohardjo; 2013.

10. Notoatmodjo S. Promosi Kesehatan Teori dan Aplikasi. Jakarta: Rineka Cipta; 2012.

11. Notoatmodjo S. Pendidikan dan Perilaku Kesehatan. Jakarta: Rineka Cipta; 2003.

12. Suharsimi Arikunto. Prosedur penelitian: suatu pendekatan praktik. Rineka Cipta; 2014.

13. Fawole AO, Hunyinbo KI, Adekanle DA. Knowledge and utilization of the partograph among obstetric care givers in south west Nigeria. Afr J Reprod Health [Internet]. 2008 Apr;12(1):22-9. Available from: http://www.ncbi.nlm.nih.gov/pubmed/20695151

14. Yisma E, Dessalegn B, Astatkie A, Fesseha N. Completion of the modified World Health Organization (WHO) partograph during labour in public health institutions of Addis Ababa, Ethiopia. Reprod Health [Internet]. 2013 Dec 18;10(1):23. Available from: https://reproductive-health-journal.biomedcentral.com/articles/10.1186/17424755-10-23

15. Abebe F. Assessment of Knowledge and Utilization of the Partograph among Health Professionals in Amhara Region, Ethiopia. Sci J Clin Med [Internet]. 2013;2(2):26. Available from: http://www.sciencepublishinggroup.com/journal/paperinfo.aspx?journalid=159\&doi=10. 11648/j.sjcm.20130202.11

16. Dorathy DT, Rebirth D, Benjamin EE, Sebastian T. Effectiveness of Structured Teaching Programme on the Knowledge and Practice of Partograph among Nurse Midwives. Int $J$ Nurs Educ [Internet]. 2018;10(2):24. Available from: http://www.indianjournals.com/ijor.aspx?target=ijor:ijone\&volume=10\&issue $=2 \&$ article $=006$ 